\title{
12. CSR-Forum würdigt Engagement
}

Im Rahmen des 12. Deutschen CSR-Forums wurde am 5. April der 7. Deutsche CSR-Preis in Ludwigsburg verliehen. Auch die Dürr Dental AG gehörte zu den Finalisten. Seit über 1 Jahrzehnt unterstützt das Medizintechnik-Unternehmen die internationale Hilfsorganisation Mercy Ships. Das Engagement reicht von Sachund Geldspenden, über gemeinsame Informationsabende, gemeinschaftliche Kongress- und Messeteilnahmen, bis hin zu ehrenamtlicher Tätigkeit von Dürr Dental Mitarbeitern. So arbeiten Ingenieure und Techniker an Bord des durch Mercy Ships betriebenen Hospitalschiffs, die Angestellten spenden ihre Zeit und die Kosten übernimmt das Unternehmen.

Die Hilfsorganisation wurde 1978 gegründet, um bedürftigen Menschen in den ärmsten Ländern unserer Erde medizinische Hilfe zu bringen. Mit der ,Africa Mercy', dem weltweit größten privaten Hospitalschiff, ist sie unterwegs an den

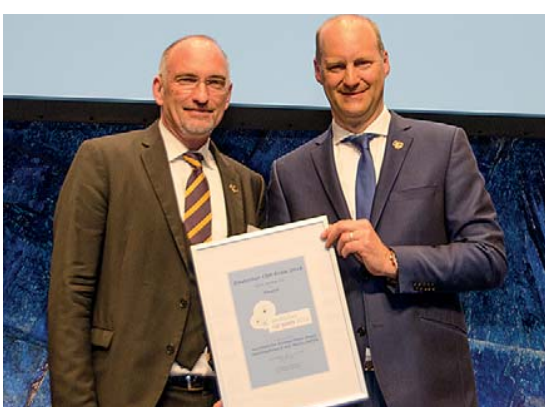

Küsten Afrikas. Mercy Ships führt an Bord dringend indizierte fachchirurgische Eingriffe durch. Darüber hinaus werden die Gesundheitssysteme in den Gastländern durch professionelle Fortbildungsmaßnahmen gefördert. Jeder Einsatz erfolgt in Zusammenarbeit mit den verantwortlichen Behörden der besuchten Länder. Auf dem Schiff mit 400 Personen Besatzung arbeiten pro Jahr rund 1600 Freiwillige aus insgesamt mehr als 40 Nationen. Bisher hat Mercy Ships Dienstleistungen im Gesamtwert von mehr als 1,2 Milliarden US-Dollar in Entwicklungsländern erbracht und somit über 2,5 Millionen Menschen zu einem besseren Leben verholfen.

Nach einer Pressemitteilung der Dürr Dental AG, Bietigheim-Bissingen

www.duerrdental.com 